\title{
Isolated Non-Pigmented Micronodular Adrenal Hyperplasia
}

National Cancer Institute

\section{Source}

National Cancer Institute. Isolated Non-Pigmented Micronodular Adrenal Hyperplasia. NCI Thesaurus. Code C131866.

A subtype of micronodular adrenal hyperplasia, characterized by multiple non-pigmented nodules. 